\title{
AS POLÍTICAS PÚBLICAS DE ESPORTE E LAZER NA CIDADE DE NOVA LIMA-MG NA GESTÃO DE 2013 A 2016
}

Recebido em: 24/12/2018

Aceito em: 22/09/2019

\author{
Aládia Cristina Rodrigues Medina ${ }^{1}$ \\ Universidade do Estado de Minas Gerais (UEMG) \\ Belo Horizonte - MG - Brasil
}

RESUMO: Este artigo tem como eixo central o tema políticas públicas municipais, objetiva compreender as políticas públicas de esporte e lazer na cidade de Nova Lima na gestão municipal que envolve o período de 2013 a 2016. A metodologia utilizada para alcance dos objetivos se caracteriza por qualitativa recorrendo à pesquisa de campo e análise de documentos. As conclusões preliminares perpassam a perspectiva de que na cidade de Nova Lima falamos de várias políticas de esporte e lazer, em função das diversas ações promovidas no período. Dessa forma, não houve uma política pública institucionalizada em relação ao tema. Vislumbra-se que há necessidade de novos instrumentos de pesquisa para complementação dos resultados identificados nesse texto.

PALAVRAS CHAVE: Esportes. Atividades de Lazer. Política Pública.

\section{PUBLIC SPORT AND LEISURE POLICIES IN CITY NOVA LIMA - MG IN MANAGEMENT 2013 TO 2016}

ABSTRACT: This article focuses on the theme axis: Public Municipal policies. It aims to understand the public sports and leisure policies in Nova Lima city from 2013 to 2016. The methodology used to achieve such objective is characterized by using field researches and document analysis. The preliminary conclusions are based on the perspective that in Nova Lima, due to various actions promoted in this period, it can not be said that there was an institucionalized public policy regarding this issue. but actually, several ones. It is necessary new research tools to complement the final results identified in this paper work.

KEYWORDS: Sports. Leisure Activitiy. Public Policy.

\footnotetext{
${ }^{1}$ Doutora em Estudos do Lazer na Universidade Federal de Minas Gerais. Membro do GESPEL - Grupo de Estudos de Sociologia, Pedagogia do Esporte e do Lazer da UFMG; do ORICOLÉ - Laboratório de estudos sobre Formação e Atuação profissional em Lazer da UFMG e do Grupo CIRANDA - Laboratório de Lazer, Infância e Cidade da UEMG. Atualmente é professora da Universidade do Estado de Minas Gerais (UEMG)
} 


\title{
Introdução
}

\author{
"Acabou a hora do trabalho \\ começou o tempo do lazer \\ você vai ganhar o seu salário \\ pra fazer o que quiser fazer \\ o que você gosta e gostaria \\ de estar fazendo noite e dia \\ ler, andar, ir ao cinema, \\ brincar com seu nenén \\ e até mesmo trabalhar também \\ quando quiser, se assim quiser \\ se assim quiser, como quiser \\ como quiser, quando quiser \\ ir de bicicleta ao mercado \\ escolher um peixe pro jantar \\ encontrar a namorada ou o namorado \\ escolher alguém pra visitar \\ quando quiser, se assim quiser \\ se assim quiser, como quiser \\ como quiser, quando quiser."
}

(Arnaldo Antunes, 2004)

"Se assim quiser", música de Arnaldo Antunes é apresentada nesta introdução para ilustrar uma concepção de lazer adotada neste artigo que tenta traduzir de forma poética o meu desejo de cidadã brasileira e ensejo de vivenciar o lazer como direito social. Esse texto é parte de pesquisa de Doutorado Interdisciplinar em Estudos do Lazer na Universidade Federal de Minas Gerais. Fazendo uma analogia à música aqui utilizada, o lazer é compreendido como “dimensão da cultura construída por meio da vivência lúdica de manifestações culturais em um tempo-espaço conquistado [“acabou a hora do trabalho, começou o tempo de lazer"] pelo sujeito ou grupo social estabelecendo relações dialéticas com as necessidades ["o que você gosta e gostaria de estar fazendo noite e dia"], os deveres e as obrigações ["e até mesmo trabalhar também"], especialmente com o trabalho produtivo" (GOMES, 2004, p. 125). 
Dessa forma, o lazer vai se estabelecer tendo quatro elementos como referência, de acordo com a autora citada, que são: tempo, espaço-lugar, manifestações culturais e ações/atitudes (GOMES, 2004), que apresento fazendo uma relação com a letra da música apresentada. Faço analogia do trecho "quando quiser" com a questão tempo de usufruir do lazer no tempo presente e não apenas em momentos específicos institucionalizados como férias, fim de semana, dentre outros; o "como quiser" referente às diferentes e diversas manifestações culturais que possibilitam a vivência do lazer como diversão, divertimento ou descanso; "se assim quiser" exemplificando as ações/atitude como expressão humana fundamentada na ludicidade, que caracteriza a livre escolha no lazer.

Portanto, compreendo que a música utilizada neste trabalho traz elementos que podem contribuir para nossa reflexão sobre o conceito e entendimento do lazer, enquanto direito social garantido pela Constituição Brasileira de 1988 a todos os cidadãos. Assim como direito à educação, saúde, ao trabalho, à moradia, segurança, dentre outros, o lazer também se encontra "garantido" na nossa legislação brasileira enquanto direito de todo cidadão.

De acordo com Marshall (1967), existem três conjuntos de direitos que compõem o conceito de cidadania. Os direitos civis, que tratam, por exemplo, do ir e vir e das questões individuais, dentre outras, os direitos políticos, que se referem a votar e ser votado, e os direitos sociais que mais me interessa aqui, que se referem ao direito de participar da vida social como um ser civilizado, acompanhando os padrões da sociedade na qual se insere (MARSHALL, 1967). Nesse sentido, o lazer é compreendido como um direito social de cada cidadão brasileiro e deve ser garantido por intermédio da intervenção do Estado por meio das políticas públicas. 
Políticas públicas são como o governo em ação. O campo das políticas públicas que estuda qual a ação, quando acontece e para que ou quem elas são formuladas. Portanto, as políticas públicas podem surgir de diferentes formas. Podem, inclusive, ser um programa de governo eleitoral que se transforma em ações por meio de projetos, planos ou programas e até em pesquisa. Esses ideais de campanha, quando postos em ação, são implementados com determinados objetivos, que, na maioria das vezes tentam resolver um problema ou uma questão da sociedade (SOUZA, 2006).

Pensar em políticas públicas significa, portanto, pensar em uma política de reordenação dos tempos e espaços de vivência de lazer das cidades, caracterizados pelos seus equipamentos de lazer, pelas competências e especificidades dos profissionais que atuam nessa área, pelos programas e projetos de efetivação desse direito social. Isto, para que "a cidade seja o espaço por excelência do encontro humano, e onde a festa aconteça em plenitude" (MARCELLINO, 2006, p. 88).

Elegi a cidade de Nova Lima - MG para realização desta pesquisa. Levei em consideração o fato de ser uma cidade representativa na região metropolitana de Belo Horizonte, por seu índice de desenvolvimento humano - o IDH de $0,813^{2}$, considerado muito alto; e por ser a maior da região em área física (LINHALES et al., 2008), que pode dar "pistas" de políticas para outras cidades com características semelhantes. Além disso, considerei a questão da acessibilidade e disponibilidade para desenvolver a pesquisa já que sou nova-limense, moradora da cidade e professora de educação física.

\footnotetext{
2 Esse índice de desenvolvimento humano da cidade de Nova Lima foi verificado no Atlas do Desenvolvimento Humano no Brasil que engloba o Atlas do Desenvolvimento Humano nos Municípios e o Atlas do Desenvolvimento Humano nas Regiões Metropolitanas. É uma plataforma de consulta ao Índice de Desenvolvimento Humano Municipal (IDHM) de 5.565 municípios brasileiros, 27 Unidades da Federação (UF), 20 Regiões Metropolitanas (RM) e suas respectivas Unidades de Desenvolvimento Humano (UDH). De acordo com o Instituto de Pesquisa Econômica Aplicada da Fundação João Pinheiro (2017), o IDH da cidade de Nova Lima é de 0,813 , fazendo com que seja considerada a melhor cidade mineira para se viver. É a primeira em um ranking entre as cidades mineiras. In: http://atlasbrasil.org.br/2013/pt/ranking acessado em 09/04/2017.
} 
Deste modo, este estudo tem como objetivo, compreender as políticas públicas de esporte e lazer na cidade de Nova Lima na gestão municipal que envolve o período de 2013 a 2016. Esse período de realização da pesquisa se justifica pelo fato de ser o período de concentração maior em termos de documentos encontrados para análise. Enquanto objetivos específicos, busca-se 1) mapear os programas, projetos e eventos de lazer da cidade promovidos pela SEMEL neste período; 2) estudar a implantação das ações desta Secretaria Municipal enquanto direito social dos cidadãos nova-limenses, respeitando o "quando quiser, se assim puder, e o como quiser" desses sujeitos no período estabelecido, à luz do Plano Diretor da cidade.

Para a realização deste estudo, recorri à pesquisa qualitativa, realizando uma pesquisa de campo. O percurso metodológico se inicia com um primeiro contato com a Secretaria de Esporte e Lazer da cidade de Nova Lima, quando precisei de alguns dados para dar continuidade ao desenvolvimento do meu projeto de pesquisa para o Doutorado sobre politicas públicas de lazer municipal. Depois disso, novos contatos foram realizados para a coleta de dados. Foram muitas visitas e conversas na Secretaria e Gabinete do vice-prefeito em busca de dados e de acessos ao acervo da Prefeitura até conseguir autorização de acessar os documentos da SEMEL que se encontram no arquivo geral da Prefeitura.

Assim, pesquisa de campo foi realizada no Arquivo Central da Prefeitura, que é o setor responsável por arquivar documentos da administração da cidade. Essa análise de documentos acontece a partir dos documentos encontrados em 65 caixas box dispostas aleatoriamente nesse espaço. Esses documentos apresentam informações que me dão suporte para compreensão do lazer na cidade por intermédio de seus programas, eventos e ações. Constituem-se como decretos, leis, comunicações internas, atas de 
reunião, relatórios, que regem a política de lazer do município, podendo “[...] nos dizer muita coisa sobre os princípios e as normas que regem o comportamento de um grupo e sobre as relações que se estabelecem entre diferentes subgrupos" (ALVESMAZZOTTI; GEWANDSZNAJDER, 1998, p. 169).

Dessa forma, analisando os dados coletados, reflito sobre a possibilidade de se construir uma cidade que pensa e promove um lazer participativo, com premissa de inclusão social, que represente a necessidade de fruir, ludicamente, as incontáveis práticas sociais constituídas culturalmente, segundo valores e interesses de sujeitos cidadãos nova-limenses, grupos e instituições deste contexto histórico, cultural e social (GOMES, 2014).

Portanto, este primeiro tópico do texto é dedicado à Introdução onde exponho objetivos, metodologia e estrutura do artigo. Já no segundo tópico busco contextualizar a cidade que é local dessa pesquisa. Em seguida conceituo o que são políticas públicas com objetivo de melhor compreender esse campo de estudos para adentrar em políticas públicas de lazer nas abrangências de nível municipal no próximo tópico, em especial no que tange à cidade de Nova Lima à luz de um importante documento da cidade, o Plano Diretor. Por fim, teço algumas considerações sobre as políticas públicas de lazer na cidade no período estudado.

\section{Nova Lima: Que Cidade É Esta?}

De "Villa Nova de Lima, cidade do ouro" à atual "cidade do minério e de condomínios de luxo". Esses são adjetivos dados à cidade de Nova Lima ${ }^{3}-$ MG,

\footnotetext{
${ }^{3}$ Em 1923 a cidade passa a se chamar Nova Lima, passados 32 anos de sua emancipação, promovida de vila à cidade, alterado pela lei estadual no. 843, de 7 de Setembro de 1923.
} 
localizada na região metropolitana de Belo Horizonte, distando da capital por aproximadamente $12 \mathrm{~km}$.

A história ${ }^{4}$ registra ter sido o Coronel Domingos Rodrigues da Fonseca Leme o primeiro branco a pisar na região da sede do município, entre os anos de 1698 e 1701, em busca de ouro e pedras preciosas. Com a notícia da rica descoberta, surgiram os primeiros faiscadores, sendo eles libertos, escravos, aventureiros, dos quais a tradição não guardou os nomes (NOVA LIMA, acessado em 23/03/2015).

Isso gerou uma grande demanda para a cidade que passou a ser considerada o paraíso do ouro nos tempos coloniais. Entretanto, somente a partir de 1836, o "Povoado" desenvolveu-se mais ordenadamente, quando a Mina do Morro Velho passou a ser explorada pela Saint John D’El Rey Mining Company Limited atualmente, Anglo Gold Ashanti ${ }^{5}$.

Nova Lima, que completou 318 anos, possui, de acordo com dados do censo demográfico do Instituto Brasileiro de Geografia e Estatística (IBGE), uma área de unidade territorial de 429.004 quilômetros quadrados, um índice de desenvolvimento humano (IDH) de 0,813 e uma população residente de 80.998 pessoas em 2010 com estimativa de ter passado a 92.178 pessoas em 2017.

A cidade foi considerada uma entre as dez melhores cidades para se viver em função desse IDH identificado como muito alto. Esse índice está relacionado a um decréscimo da população rural e aumento expressivo da população do município,

\footnotetext{
4 A história de Nova Lima pode ser consultada de forma bem descritiva no site http://historianovalima.no.comunidades.net/ que apresenta a saga dos mineiros na Mina de Morro Velho, o distrito de São Sebastião das Águas Claras, hoje denominada Macacos e o distrito de Honório Bicalho, além de história de nome da cidade, bairros e ruas, apresentando ainda, fotos históricas e vídeos.

${ }^{5}$ De acordo com o site da empresa, http://www.anglogoldashanti.com.br/acessado em 19/04/2015, "no século XIX, a empresa de mineração inglesa Saint John Del Rey Mining Company deu início à exploração de ouro em Nova Lima, Minas Gerais. Mais de 170 anos depois, o patrimônio minerador passou a ser controlado pela AngloGold, atualmente AngloGold Ashanti, após a fusão com a Ashanti Goldfields, em 2004. A empresa explora minério de ouro no Quadrilátero Ferrífero, província mineral com grande importância para o desenvolvimento econômico e social de Minas Gerais e do país
} 
provocados pelo crescimento dos condomínios horizontais e verticais, decorrentes da expansão mobiliária pela qual vem passando desde 1980, sendo a década de 2010, marco da expansão considerável na população urbana, principalmente nos condomínios que circundam a cidade na MG-30. Isso se deu como resultado da expansão territorial do setor Sul de Belo Horizonte pela busca de melhoria da qualidade de vida e fuga do estresse proporcionado pela cidade grande (SOUZA, 2013).

Dados do IBGE nos mostram que a cidade, em 2014 apresentava um PIB per capita de $\mathrm{R} \$ 103282,14$ e salário mensal dos trabalhadores formais de 3,8 salários mínimos em 2015 , tendo $29,6 \%$ da população na condição de rendimento mensal de até 1/2 salário mínimo por pessoa. A taxa de mortalidade infantil média na cidade é de 6,49 para 1000 nascidos vivos. Com relação ao saneamento básico, foi considerado que 94\% dos domicílios apresenta esgotamento sanitário adequado.

Com relação aos índices de pobreza, os últimos dados do $\mathrm{IBGE}^{6}$ revelam que a incidência de pobreza encontra-se na faixa dos $11,05 \%$ (sendo limite inferior, 4,75\% e superior 17,36\%). Um dado bastante interessante é o índice de Gini que mede o fator de desigualdade social das cidades, é um dado estatístico que avalia a distribuição de riqueza de um determinado lugar medindo a desigualdade social e o nível de concentração de riqueza. $\mathrm{O}$ valor encontrado para esse cálculo para a cidade foi de 0,4. Vale ressaltar que os dados vão de 0 a 1 , onde 0 corresponde a completa igualdade na renda e 1 caracteriza a completa desigualdade. "O Coeficiente de Gini é amplamente utilizado para subsidiar processos decisórios de políticas públicas, principalmente quando se trata de definir ações regionalizadas" (RAMALHO JÚNIOR, 2012, p. 76). Esse dado auxilia na identificação de diferenças inter-regionais e pode auxiliar na

\footnotetext{
${ }^{6}$ Confira dados em: https://cidades.ibge.gov.br/v4/brasil/mg/nova-lima/pesquisa/36/30246
} 
orientação das ações diferenciadas visando eliminar esses desequilíbrios direcionando as políticas públicas.

Nessa perspectiva, posso inferir que a cidade, tem um IDH alto em função desse crescimento da população em condomínios de luxo nos seus arredores. Entretanto, também apresenta desigualdade social e é significativa a incidência de pobreza da população. Assim, esse dado de índice de desenvolvimento humano não pode ser um dado analisado isoladamente. Os demais índices apresentados também dão pistas da necessidade de políticas públicas que promovam a igualdade, a equidade e a efetividade de acesso aos direitos aos nova-limenses.

\section{Políticas Públicas}

As ações políticas, na prática, são responsáveis por materializar os direitos do cidadão por intermédio de políticas públicas. Mas o que são as políticas públicas? Antes mesmo de conceituar o termo, é interessante e necessário refletir sobre a origem do mesmo para que possamos problematiza-lo, entender seus desdobramentos e suas perspectivas. Para isto me basearei na Souza (2006) que trata dos principais conceitos e modelos de análise de políticas públicas. Enquanto área de conhecimento e disciplina acadêmica, as políticas públicas surgem nos Estados Unidos, diferentemente da Europa, com ênfase no estudo sobre a ação dos governos. Nos Estados Unidos, a vertente que fala sobre ciência política veio se instituir no início dos anos 50 sob o rótulo de policy science, ao passo que na Europa essa preocupação só ganha força a partir dos anos 70 (FREY, 2000).

De acordo com Souza (2006) quatro nomes podem ser citados como fundadores da área das politicas públicas: 1) Laswell (1936) introduz a expressão Policy analysis 
que significa análise de políticas públicas na perspectiva de conciliar o conhecimento produzido cientificamente pela área associado à ação dos governos estabelecendo diálogo entre cientistas sociais, governo e grupos de interesse (SOUZA, 2006). 2) Simon (1947) introduz o termo policy makers que explica a racionalidade limitada dos decisores políticos por informações incompletas ou imperfeitas, tempo para a tomada de decisões, auto interesse, dentre outros. Entretanto essa racionalidade pode se tornar positiva se estruturas forem criadas para moldar comportamento dos atores, impedindo até a maximização da busca de interesses próprios. 3) Lindblom $(1959 ; 1979)$ vem questionar o racionalismo citado anteriormente e incorpora outras variáveis à formulação e análise de políticas públicas, como a questão das relações de poder, papel das eleições, burocracias etc; e 4) Easton (1965) que define políticas públicas como um sistema que "recebem imputs dos partidos, da mídia e dos grupos de interesse, que influenciam seus resultados e efeitos" (SOUZA, 2006, p. 24).

Ao falar da temática na Ciência Política, Frey (2000) aponta que nessa perspectiva há três abordagens de acordo com os problemas de investigação levantados: pode ser um questionamento do que se trata um bom governo e qual é o melhor Estado para garantir e proteger a felicidade dos cidadãos ou de uma determinada sociedade; a segunda com um questionamento político no sentido de analisar as forças cruciais no processo decisório e finalmente as investigações que podem ser voltadas aos resultados $^{7}$. E ainda que esta se diferencia em dimensões na política: 1) a dimensão institucional - 'polity' que 'se refere à ordem do sistema político, delineada pelo

\footnotetext{
${ }^{7}$ Para maiores detalhamentos sobre Policy analysis, consultar Klaus Frey (2000) em seu artigo intitulado: Políticas Públicas: um debate conceitual e reflexões referentes à prática da análise de políticas públicas no Brasil apresentado na Revista Planejamento e Políticas Públicas no. 21 de Junho de 2000. O artigo aborda detalhadamente o termo analítico 'policy analysis' apresentando conceitos dos termos policy, polity, policy network, policy arena e policy cycle na perspectiva da Ciência Política. Caracteriza os tipos de políticas, categorizando-as de acordo com seu caráter distributivo, redistributivo, regulatório ou constitutivo.
} 
sistema jurídico, e à estrutura institucional do sistema político administrativo" (FREY, 2000, p. 216); 2) a dimensão processual - 'politics' que se refere ao processo político normalmente de caráter conflituoso, "no que diz respeito à imposição de objetivos, aos conteúdos e a decisões de distribuição"(idem) e a 3) dimensão material - 'policy' que se refere aos programas políticos, problemas técnicos e decisões políticas. Portanto, de forma bem sucinta, "o primeiro termo designa as instituições políticas; o segundo, os processos políticos; e o último os conteúdos da política" (STAREPRAVO, 2011, p. 241).

No que tange às definições de políticas públicas, são vários os conceitos que podemos citar, entretanto o que é assumido nesta pesquisa é que a política pública tratase do governo em ação. O que fazer, por que fazer, para que e para quem fazer, concretizando os planos de uma proposta política transformado em ação para resolução de um problema ou questão da sociedade. Dessa forma, na perspectiva teóricoconceitual a política pública e a política social são campos multidisciplinares (SOUZA, 2006; MARQUES e FARIA, 2013). "Por isso, uma teoria geral da política pública implica a busca de sintetizar teorias construídas no campo da sociologia, da ciência política e da economia" (SOUZA, 2006, p. 25). Precisa explicar uma inter-relação entre Estado, política, economia e sociedade, como

[...] um campo do conhecimento que busca, ao mesmo tempo, 'colocar o governo em ação' e/ou analisar essa ação (variável independente) e, quando necessário, propor mudanças no rumo ou curso dessas ações (variável dependente). A formulação de politicas e ações públicas constitui-se no estágio em que os governos democráticos traduzem seus propósitos e plataformas eleitorais em programas e ações que produzirão resultados ou mudanças no mundo real. [...] Políticas públicas, após desenhadas e formuladas, desdobram-se em planos, programas, projetos, bases de dados ou sistema de informação e pesquisas. Quando postas em ação, são implementadas, ficando daí submetidas a sistemas de acompanhamento e avaliação (SOUZA, 2006, p. 26). 
Política pública pode ser também considerada e entendida como uma estratégia de intervenção do Estado, ou seja, daqueles responsáveis pela administração das ações que objetivam alcançar determinados resultados ou produzir efeitos no que diz respeito a um problema ou um setor da sociedade (MENICUCCI, 2006). "São decisões que envolvem questões de ordem pública com abrangência ampla e que visam à satisfação do interesse de uma coletividade. (AMABILE, 2012, p. 390). Nesse sentido, é o Estado, através dos agentes que o administram, quem elabora as politicas públicas para os mais variados setores (STERAPRAVO, 2011), passando a se responsabilizar pela garantia de que direitos e deveres sejam cumpridos nos mais diversos setores. Estudar política pública significa estudar o governo em ação. As políticas públicas influenciam e são influenciadas por valores e ideais que orientam a relação entre Estado e sociedade.

A ação é resultante de um ciclo, constituído de um processo dinâmico e de aprendizado, que acontece nos seguintes estágios: “definição da agenda, identificação de alternativas, avaliação das opções, seleção das opções, implementação e avaliação" (SOUZA, 2006, p. 30). De acordo com Amabile (2012) as políticas públicas se constituem de 4 etapas: formulação, execução, monitoramento e avaliação. Essas abordagens caracterizam a definição da agenda que pode ser formulada focando nos problemas, assumindo que é necessário fazer algo sobre eles; com ênfase na política propriamente dita, ou seja, construir a consciência sobre a necessidade de se fazer algo; e o terceiro foco na decisão da agenda refere-se aos participantes que podem ser a mídia, políticos, acadêmicos, partidos, grupos de pressão. Esses definem as agendas e as alternativas. Pode-se perceber que é o governo quem toma as decisões sobre as situações-problema e desenha as políticas para saná-las ou minimizar as questões consideradas problemáticas (SOUZA, 2006). 
Ainda na perspectiva de Souza (2006), os principais elementos das políticas públicas são:

[...] permite distinguir entre o que o governo pretende fazer e o que, de fato, faz. Envolve vários atores e níveis de decisão, embora seja materializada através dos governos, e não necessariamente se restringe a participantes formais, já que os informais são também importantes. É abrangente e não se limita a leis e regras. É uma ação intencional, com objetivos a serem alcançados. Embora tenha impactos no curto prazo, é uma política de longo prazo. Envolve processos subsequentes após sua decisão e proposição, ou seja, implica também implementação, execução e avaliação (SOUZA, 2006, p. 36-37).

A autora afirma que, dessa forma, as políticas irão se materializar de acordo com um sistema político que vai gerar pontos ou grupos de vetos e de apoios diferentes, numa disputa em torno de sua decisão.

Vale ressaltar que existem quatro formatos ou tipos de políticas públicas: as distributivas - decisões do governo de acordo com grupos gerando impactos mais individuais que coletivos; as regulatórias - envolvem burocracia, políticos e grupos de interesse; as políticas redistributivas - em geral, são as politicas universais; e por último, as políticas constitutivas - lidam com os procedimentos. Já para Frey (2000) essas quatro formas de política caracterizam a forma e os efeitos dos meios de implementação aplicados, aos conteúdos das políticas, no que diz respeito á solução dos conflitos políticos.

Para além de definições e conceitos, alguns autores (FREY, 2000, STAREPRAVO, 2011) corroboram o fato de que o estudo de políticas públicas de lazer no Brasil é ainda muito recente e incipiente, dando ênfase, na maioria das vezes, a dois aspectos: à análise das estruturas e instituições ou à caracterização dos processos de negociação das políticas setoriais específicas. "Normalmente, tais estudos carecem de um embasamento teórico que deve ser considerado um pressuposto para que se possa 
chegar a um maior grau de generalização dos resultados adquiridos" (FREY, 2000, p. 215).

A Constituição Brasileira de 1988 garante a todos os brasileiros o lazer enquanto direito social. O trabalho desenvolvido por $\operatorname{Santos}^{8}$ (2011) nos mostra como o lazer entrou na pauta da discussão para ser considerado um direito social na nossa Constituição. A autora concluiu que o lazer não se configurou nem por intermédio de setores comerciais, tão pouco por interesses ideológicos. Ele surge nas discussões por meio de compreensões individuais, sendo possível percebê-lo através das relações construídas entre ele e a saúde, o esporte, turismo e cultura. Sendo, de qualquer maneira, entendido como "atividade por alguns, direito fundamental por muitos, como importante à realização integral do ser humano e possibilidade de novas aprendizagens por outros e como uma necessidade básica dos cidadãos por muitos outros" (SANTOS, 2013, p.7).

Dessa forma, no que tange às políticas públicas de lazer, apesar de estar presente na Constituição de forma evidente, esse fenômeno aparece muito restrito às questões esportivas (MARCELLINO, 1996), pois esporte e lazer são apresentados, na maioria das vezes, numa perspectiva conjunta, como direitos sociais. Para além disto, verificase que o lazer, assim como o esporte, não tem a mesma prioridade ou preocupação dados a setores como educação, saúde, habitação e outros. Existe uma lacuna relacionada aos estudos de políticas públicas voltados para esse setor. "Tal carência [...]

\footnotetext{
${ }^{8} \mathrm{O}$ trabalho citado se refere à Dissertação: "Procurando o lazer na Constituinte: sua inclusão como direito social na Constituição de 1988" da autora: Flávia da Cruz Santos (2011), orientada pela profa. Dra. Silvia Cristina Franco Amaral, que traz o resultado de um trabalho intenso de análise de documentos sobre como o lazer se transformou em direito social na Constituição de 1988. Algumas de suas conclusões: que existiram muitas maneiras de compreender o lazer na Assembleia Nacional Constituinte, que a inclusão do lazer no artigo que define os direitos sociais foi obra dos constituintes, foram eles os responsáveis por isso, pela definição do lazer como direito social na Constituição de 1988. Também foi possível perceber os jogos de poder e de interesse envolvidos na construção da Constituição de 1988.
} 
justifica-se ao grau de importância que as temáticas tem em relação à definição de políticas públicas na esfera federal” (SUASSUNA, 2007, p. 13-14).

Pensando sobre essa carência na efetivação do acesso ao direito ao lazer e de políticas públicas que garantam isso, questiono: como garantir que esse direito seja realmente efetivado a todos os cidadãos brasileiros? Só de estar presente na Constituição é garantia de que irá acontecer? Sim, o direito ao esporte e ao lazer já está garantido na Constituição. Entretanto, o acesso a esse direito é o que deve ser garantido pelas políticas públicas. É consenso que essa temática começou a ganhar força, então, a partir da Constituição Federal Brasileira de 1988, mas outro fator muito importante para disseminação dessa temática tanto no campo acadêmico como científico foi a criação do Ministério do Esporte no ano de 2003. Foi quando o setor ganhou "status" de pasta única governamental, o que proporcionou a criação de novas ações políticas (SILVA, BORGES; AMARAL, 2015).

Nesse âmbito, um Ministério foi instituído para ser responsável pela efetivação de políticas públicas voltadas para garantir o lazer como direito, em nível federal, tratase do Ministério do Esporte, criado por meio da medida Provisória 103/2003

[...] com o objetivo de 'Formular e implementar políticas públicas inclusivas e de afirmação do esporte e do lazer como direitos sociais dos cidadãos, colaborando para o desenvolvimento nacional e humano' (MEDIDA PROVISÓRIA 103/2003). Para a formulação e planejamento de políticas nos âmbitos do esporte e lazer, acreditava-se que a criação de uma pasta ministerial para tratar do esporte propiciaria a ampliação do debate sobre esse tema, contribuindo para legitimar a discussão e conferindo ao esporte, bem como ao lazer, um redimensionamento (SUASSUNA et al., 2007, p. 29).

Esse redimensionamento refere-se a ações do governo e a uma nova forma de se pensar o lazer, no sentido de tratar o esporte e o lazer como políticas concretas, com foco na inclusão social. Assim, a tarefa do Ministério do Esporte é "assegurar e facilitar 
o acesso de todos a atividades esportivas e de lazer [...] (que) são direitos sociais e, por isso, interessam à sociedade [...] colaborando para a construção da cidadania" (SILVA et al., 2011a, p. 53).

Reitero que facilitar e assegurar o acesso às atividades de lazer significa pensar em politicas públicas de lazer e esporte no Brasil. Porém, pensar e discutir políticas públicas de lazer e esporte no Brasil é algo recente, que foi estimulado pelo crescimento das possibilidades de consumo de bens e serviços pelos cidadãos e pela organização da sociedade civil e do poder público, que passam a refletir sobre essa necessidade de assegurar o direito constitucional ao lazer e suas possibilidades de vivências no plano cultural (BONALUME; ECHER, 2009). Para isso depende-se de ações políticas que são discutidas nas instâncias dos diferentes entes federativos, sobretudo na perspectiva federal.

\section{Políticas Públicas de Esporte e Lazer Municipais}

Tem sido crescente o número de pesquisas que têm como temática central as políticas públicas de lazer municipais. É interessante pois na medida em que considero que a política pública é o governo em ação, essa ação está mais próxima do usuário quando ela se concretiza no âmbito das cidades, interferindo na vida das pessoas. Estudos me fazem acreditar que essa temática é relevante e que necessita cada vez mais de investidas nessa área.

Marcellino (1996a), quando se refere ao papel da administração municipal, salienta alguns aspectos que devem ser levados em consideração e para discussão nesse âmbito. São eles: 1) as prefeituras deveriam considerar de forma ampla os interesses do lazer, articulando, inclusive, com diferentes secretarias municipais; 2) considerar o 
duplo processo educativo do lazer: educar para e pelo lazer - objeto e instrumento do lazer; 3) considerar as possibilidades do lazer enquanto instrumento de mobilização e participação cultural; 4) considerar as barreiras socioculturais verificadas - como a questão econômica, por exemplo - para possibilitar acesso às camadas da população que normalmente não são atendidas; 5) considerar os limites da administração pública, o que requer incentivar e participar das discussões e ações junto aos órgãos de classe e outros setores da sociedade civil.

O livro "Um olhar sobre a trajetória das políticas públicas de esporte em Minas Gerais: 1927 a 2006 organizado por Rodrigues e Isayama (2014) tem como objetivo analisar a trajetória das políticas públicas de esporte e lazer em Minas Gerais de 1927 a 2006. Essa pesquisa foi realizada no Centro de Memória e Informação do Esporte (CEMIE), da Secretaria de Estado de Esporte e da Juventude.

$\mathrm{Na}$ perspectiva analisada, com atenção para as instituições, o esporte foi promovido, em âmbito estadual, inicialmente pelo Diretoria de Esportes de Minas Gerais (DEMG) que atuou de1946 a 1987; depois pela Secretaria de Esporte, Lazer e Turismo (SELT), atuando de 1983 a 1996; em seguida pela Secretaria de Estado de Esporte (SEESP) criada em 1996; e ainda pela Secretaria de Estado de Desenvolvimento Social (SEDESE), criada em 2003, "quando o esporte deixou de ter uma secretaria específica, passando a ser tratado por uma subsecretaria articulada a outras pastas da ação social sem, no entanto, atuar de modo integrado a elas e demais secretarias" (PINTO, 2014, p.13).

Essa pesquisa conclui que o esporte mineiro foi historicamente utilizado para diferentes fins. A história demarca a década de 1930 para entrada dos interesses do Estado no esporte, mas os registros dessa pesquisa mostram que essa investida acontece 
a partir de 1927, com uma política de promoção da Educação Física voltada para programas de atividades físicas para as crianças como forma de educar os corpos.

No período da DEMG, durante os 41 anos de existência, o Estado promoveu uma política de implementação de praças de esporte e ruas de recreio. Além disso, criou a Escola de Educação Física, cursos de qualificação, auxiliou de forma significativa a estruturação do Conselho Regional de Desportos (CRD) e ainda apoiou agremiações esportivas por meio de subvenções e auxílios (RODRIGUES; COSTA, 2014).

O período de 1983 a 1996 (SELT) foi caracterizado pela construção de obras esportivas por todo o Estado, as Praças de Esporte, e ainda diversas ações como os Jogos do Interior de Minas Gerais - JIMI e o Programa Curumim reconhecido pelo grande apelo social e que serviu de modelo para outros estados. Era a política de assistência às populações carentes que utilizava o esporte como solução de problemas sociais. A conclusão da pesquisa sobre o esporte e o lazer no período da SELT apresenta uma não legitimidade dos direitos do esporte e lazer como setores das políticas sociais para todos, pois as ações foram vinculadas à estratos sociais (VIANA; OLIVEIRA, 2014).

A criação da Secretaria de Estado de Esportes de Minas Gerais foi um momento histórico importante no processo de políticas públicas de esporte em Minas, atuando de 1996 a 2002. Entretanto as conclusões da pesquisa anunciam a falta de entendimento amplo do esporte e lazer, promovendo então políticas de cunho assistencialista focada em grupos definidos e de forma utilitária. O público priorizado nas ações da SEESP foi a criança, o adolescente e o jovem com o discurso de prevenção de violência para os sujeitos em vulnerabilidade social. As ações foram mais voltadas à prática esportiva de competição sendo o "lazer" associado "as ruas de lazer" e "esporte recreativo". Dessa 
forma, as autoras encerram o texto desejando uma "gestão pública que promova o direito ao lazer e ao esporte, pautado pela autonomia e pela qualidade de vida da população" (SILVEIRA; SILVA, 2014, p. 203).

A história das políticas públicas de esporte e lazer em Minas Gerais no período de 2003 a 2006 foi retratada por intermédio da Secretaria de Desenvolvimento Social e Esportes, denominada SEDESE. Esse órgão foi criado em um momento administrativo complexo no qual o Estado passava por um "choque de gestão". Foi criada com finalidade de planejar, coordenar, executar e avaliar as ações do governo do estado que assumiam o discurso de desenvolvimento social, por meio de ações relacionadas ao trabalho, emprego, esporte, lazer, direitos humanos, prevenções e assistência social. Apesar dessa perspectiva, a intersetorialidade não foi identificada nas ações entre os programas e projetos desenvolvidos na área esportiva e de lazer com as demais políticas sociais. Isayama e Peres (2014) nesse estudo identificaram que os conceitos de lazer e esporte eram utilizados de forma diferenciada, sendo o esporte visto como possibilidade de desenvolvimento de atleta de alto rendimento e como oportunidade de desenvolvimento social. Já o lazer foi entendido como "compensação dos problemas sociais, bem como o entendimento como evento ou entretenimento que acontece em períodos determinados como finais de semana e feriados" (ISAYAMA, PERES, 2014, p. 241).

Esse panorama das políticas públicas de esporte e lazer no âmbito do estado de Minas Gerais nos leva a refletir sobre a importância de estudos e pesquisas sobre políticas públicas de lazer, em especial nas cidades, em função das trajetórias políticas em um estado no qual o esporte e lazer ainda não são entendidos e vividos enquanto 
direito social. Observei, em outros levantamentos, que há poucas trajetórias relatadas sobre a cidade de Nova Lima., na perspectiva de políticas públicas.

Há três pesquisas que envolvem a região metropolitana de Belo Horizonte, abordando 13 cidades dentre elas a referida nesta pesquisa. A pesquisa intitulada "Esporte e lazer na Grande-BH. Por onde caminham as políticas públicas?" de Linhales et. al (2008) foi uma pesquisa realizada no período compreendido entre dezembro de 2005 a junho de 2007 e teve como objetivo entender como o esporte e o lazer se organizam na gestão pública municipal. Para alcance dos objetivos foram elencados alguns eixos para análise e problematização dos dados, sendo: conceito de esporte e de lazer, perfil do gestor, quadro de profissionais da Secretaria; ações de formação e capacitação, estrutura física disponível para a gestão, relação entre parcerias publicas, privadas e dotação orçamentária. Ainda avaliaram as ações: os programas, projetos e eventos esportivos, relação com as ligas de futebol e a inclusão social.

O estudo concluiu que a história dos gestores estavam vinculadas ao esporte de rendimento, em especial o futebol, fazendo a relação entre a ocupação de um cargo público de uma secretaria de esportes e a experiência como atleta profissional como algo já "naturalizado". Os arranjos políticos na distribuição de cargos públicos também foram levantados. No conjunto das ações das secretarias analisadas foi verificado que as práticas competitivas ganham destaque no conjunto das ações. Quanto à formação dos profissionais, "o que surgiu de mais recorrente na fala dos entrevistados é o fato de que, para atuar na área, o gestor precisa ter uma vivência com alguma modalidade esportiva, e não necessariamente uma formação profissional voltada para essa atuação" (LINHALES et.al, 2008, p. 52). E o texto ainda finaliza sinalizando uma dificuldade de rompimento com práticas centralizadoras, setorializadas e pautadas por pouca ou até 
nenhuma participação popular, independente de partido político, o que permitiu inferir que não há um debate qualificado no sentido de democratização do esporte e lazer nas cidades pesquisadas.

O trabalho desenvolvido por Isayama et al. (2011), denominado "Lazer, políticas públicas e formação profissional : Análise da política de formação profissional de secretarias de Esporte de municipios da Região Metropolitana de Belo Horizonte" também adota o recorte da pesquisa de Linhales et al. citada anteriormente, com as 13 cidades entretanto na perspectiva da análise da formação profissional, objetivando identificar, descrever e analisar a política de formação profissional desenvolvida pelas secretarias municipais de Esporte de municípios da Grande BH. As referências utilizadas foram "o conteúdo desenvolvido, a compreensão sobre o esporte e o lazer e a importância atribuída a essas ações por esses órgãos de governo" (ISAYAMA et. al, 2011, p. 212).

A pesquisa conclui que não há uma política de formação profissional, o que é considerado secundário. As ações desenvolvidas nas Secretarias da região metropolitana são ações isoladas com perspectiva técnica e instrumental, ligadas à aptidão física e ao rendimento esportivo. A formação é incentivada ou até financiada quando a demanda surge do próprio profissional. Em alguns municípios, as ações de formação propostas pelo Ministério do Esporte em parceria com os municípios "são as únicas possibilidades de formação que atuam para além da dimensão técnica e instrumental" (ISAYAMA et. al, 2011, p.226). Por fim, conclui que o esporte e o lazer não são entendidos como direitos sociais, fundamentais á cidadania à melhoria da qualidade de vida dos sujeitos.

Ainda nessa mesma perspectiva, o artigo "A inclusão social presente nos discursos dos dirigentes municipais de esporte/lazer da Grande-BH" de Lopes et al. 
(analisa as representações de inclusão presentes nos discursos dos dirigentes das Secretarias dessas cidades, que, inclui a cidade de Nova Lima). O estudo demonstra que a preocupação com a inclusão social nas políticas públicas de lazer foi citada por 7 dos 12 dirigentes municipais entrevistados, entretanto, na perspectiva de assistencialismo e paternalismo. O esporte lazer é entendido com diferentes abordagens: associado ao setor de desenvolvimento social e educação; como solução para retirada de crianças do crime e da violência; para solução da desigualdade social; para disciplinarização dos corpos e das condutas. Vale ressaltar a ideia de que oferecer a ampliação dos equipamentos de lazer por si só, constitui possibilidade de inclusão social. O estudo conclui a diversidade das abordagens do termo inclusão social e como isso se apresenta como um dos principais desafios e justificativas para as políticas sociais brasileiras. Porém salienta os grandes equívocos conceituais nas falas dos sujeitos.

Em suma, esse panorama apresentado e as contribuições desses trabalhos reforçam meu interesse em estudar as políticas públicas de lazer na cidade de Nova Lima - MG e aprofundar nos conhecimentos acerca do lazer promovido pelos municípios na perspectiva do entendimento do lazer enquanto direito social. Para isso, no capítulo seguinte retrato especificamente as políticas de lazer da cidade estudada.

\section{Politicas Públicas de Esporte e Lazer em Nova Lima}

\section{O Plano Diretor Vigente}

Sobre gestão municipal e política de lazer, Castellani Filho (2006) nos esclarece sobre o Estatuto da Cidade que é o instrumento do município para o exercício do desenvolvimento das funções sociais da cidade (grifos da autora). Esse instrumento é tão importante que "visa garantir a possibilidade da participação da população em todas 
as decisões de interesse público, preservando-a - através de suas associações representativas - no processo de elaboração, implantação e avaliação do plano diretor [...] (p. 121-122), além do acesso ao serviço e toda melhoria realizada pelo poder público. Dessa forma, é o Estatuto da Cidade que torna obrigatória a elaboração do Plano Diretor para os municípios com população acima de 20 mil habitantes e os situados em regiões metropolitanas, como é o caso da cidade em questão - Nova Lima, Minas Gerais. O Plano Diretor deve garantir que todas as necessidades dos cidadãos do município sejam satisfeitas de forma adequada e digna: habitação, saneamento, transporte, lazer, dentre outros.

Não obstante, Castellani Filho (2006) nos lembra que "três perguntas se fazem (ou deveriam se fazer) presentes quando a questão do Plano Diretor está em pauta: 1) que município temos? 2) que município desejamos? 3) que acordo podemos firmar para alcançar a situação desejada?" e ainda se vale destas para adaptar ao campo do lazer: “1) que lazer temos? 2) que lazer desejamos? 3) que acordo podemos firmar para alcançar a situação desejada?” (2006, p. 124). Com isso questiona-se: podem-se fazer essas perguntas com relação à cidade a ser pesquisada? Acredito que esta transposição possa ser feita, mas não sem antes situar-se o locus da pesquisa.

Dessa forma, para falar sobre as políticas públicas de lazer de Nova Lima, utilizo do primeiro documento da coleta de dados que considero importante que é o Plano Diretor da cidade de Nova Lima. Ele é considerado o instrumento legal que normatiza toda política municipal de desenvolvimento econômico, social, urbano e ambiental do Município, assim como representa o instrumento básico de planejamento e gestão municipal nos âmbitos público e privado. 
Esse importante documento foi balizado pelas diretrizes da justiça e inclusão social; redução das desigualdades sociais e regionais; descentralização e coordenação da administração pública; pela participação da população nos processos de decisão, planejamento, gestão, implementação e controle do desenvolvimento urbano; que tem como objetivos prioritários: "elevar a qualidade de vida da população, priorizando a inclusão social no que se refere à saúde, à educação, ao trabalho e à renda, à cultura, às condições de moradia, à infraestrutura urbana e aos serviços públicos com redução das desigualdades econômicas e sociais" (NOVA LIMA, 2007, p.6).

O Plano diretor da cidade é registrado na lei $\mathrm{n}^{\circ} 2007$, de 28 de agosto de 2007, foi um documento muito importante para a localidade, porque, dentre outras coisas, foi discutido junto à população. Entretanto, ficou um tempo para análise na Câmara Municipal onde sofreu inúmeras alterações no seu texto final.

No que tange ao campo específico estudado, verifica-se que a seção VIII trata do Esporte e lazer, nos seus artigos 29 e 30, afirmando que são objetivos da política do Esporte e Lazer:

I. propiciar condições de desenvolvimento físico, mental e social, através do incentivo à prática de atividades esportivas e recreativas, considerando direito do cidadão e dever do Município;

II. manter em funcionamento pleno as áreas livres municipais destinadas ao esporte e ao lazer;

III. oferecer acesso universal e integral às práticas esportivas, promovendo bem-estar e melhoria da qualidade de vida (NOVA LIMA, 2007, p. 21).

E apresenta as diretrizes da Política de Esporte e Lazer da cidade no artigo 30:

I. a recuperação dos equipamentos de esportes, adequando-os à realização de eventos esportivos;

II. a garantia do acesso dos portadores de necessidades especiais aos equipamentos esportivos municipais; 
III. a ampliação e a otimização da capacidade dos equipamentos esportivos municipais;

IV. a identificação de áreas que necessitam de equipamentos visando à ampliação da oferta da prática de esporte e lazer;

V. incentivar a prática esportiva e recreativa, propiciando condições de desenvolvimento pessoal e social;

VI. orientar a população para a prática de atividades em áreas verdes, parques, praças e áreas livres;

VII. estimular a prática de jogos tradicionais populares;

VIII. criar o Conselho Municipal de Esporte e Lazer (COMEL), envolvendo as entidades representativas na mobilização da população e na execução das ações esportivas e recreativas;

IX. criar e implantar o Fundo Municipal de Esporte e Lazer (FUMEL);

$\mathrm{X}$. garantir a toda população, condições de acesso e de uso dos recursos, serviços e infraestrutura para a prática de esportes e lazer;

XI. incentivar a prática de esportes na rede escolar municipal através de programas integrados à disciplina Educação Física;

XII. implementar e apoiar iniciativas de projetos específicos de esporte e lazer para todas as faixas etárias;

XIII. apoiar a divulgação das atividades e eventos esportivos e recreativos;

XIV. descentralizar e democratizar a gestão e as ações em esporte e lazer, valorizando-se as iniciativas das associações comunitárias de bairros;

$\mathrm{XV}$. desenvolver programas de apoio à prática de esportes amadores;

XVI. ampliar os programas de eventos poliesportivos e de lazer e entretenimento;

XVII. assegurar o pleno funcionamento de todos os equipamentos, garantindo a manutenção de suas instalações;

XVIII. promover jogos e torneios que envolvam as associações comunitárias dos bairros, dos municípios vizinhos e de outros estados; XIX. elaborar e propor legislação de incentivo às atividades de esporte e lazer, incluindo a possibilidade do estabelecimento de parcerias;

XX. revitalizar e assegurar pleno funcionamento dos Poliesportivos Municipais;

XXI. criar alternativa físico-financeira para construção do Centro Olímpico Municipal;

XXII. manter e ampliar o programa de ruas de lazer, promovendo atividades de esportes, lazer e recreação;

XXIII. viabilizar parcerias com escolinhas de futebol e demais esportes;

XXIV. construir ciclovias, rampas de skates, piscinas olímpicas nos poliesportivos municipais (NOVA LIMA, 2007, p. 21-22).

A Secretaria Municipal de Esporte e Lazer (SEMEL) criada em 1997 - é responsável pelo planejamento, elaboração, execução e avaliação dos projetos de lazer na e para a cidade, em articulação com outras secretarias. A fim de compreender um 
pouco mais esse espaço, as informações obtidas junto ao órgão responsável em planejar e efetivar as ações de lazer que estão resguardadas no Plano Diretor citado anteriormente foram apresentadas em cartilha desenvolvida por esta Secretaria datada de 7 de janeiro de 2014, e contém as diretrizes organizacionais da SEMEL, a saber:

a) Missão: contribuir para a difusão do esporte e do lazer para o progresso da educação e para a melhoria da qualidade de vida no seio da comunidade de Nova Lima. b) Valores: transparência, ética, trabalho em equipe, respeito pelas pessoas com as quais trabalhamos e pensamento sempre à frente, de forma estratégica e inovadora. c) Visão: tornar Nova Lima uma referência no esporte e no lazer no Estado de Minas Gerais.

A partir da análise do material desenvolvido pelo setor, pesquisado nos arquivos da Secretaria, descobri que na Secretaria havia em torno de setenta professores de Educação Física que atuavam como agentes em esporte educacional, esporte saúde e esporte rendimento, distribuídos em vários projetos e ações. Projetos como: campeonatos, jogos, maratonas, torneios, colônia de férias, gincanas, academia ao ar livre, festas especificas da cidade, manutenção de campos e quadras, festivais como o de esportes radicais e skate, até mesmo a realização da primeira Conferência Municipal do Esporte e do Lazer na cidade de Nova Lima, com a participação da população, onde foram discutidos e aprovadas as:

[...] diretrizes da Política Municipal do Esporte e do Lazer; o Sistema Municipal do Esporte e do Lazer; o Plano Municipal do Esporte e do Lazer; eleição dos conselheiros efetivos e suplentes, representantes da sociedade civil; indicação dos conselheiros efetivos e suplentes, representantes do Governo Municipal (ARAÚJO, 2014, s/p.).

Essa Conferência foi uma ação importante e inédita na cidade e teve a participação e envolvimento da sociedade civil, das pessoas envolvidas com futebol amador e de representantes do esporte na cidade que compuseram o Conselho Municipal de esporte e lazer. Dessa forma, a cidade tem as diretrizes que orientam o 
esporte e o lazer no Plano Diretor, tem o Conselho instituído, há uma Política Municipal de Esporte e Lazer e um Sistema Municipal de Esporte e Lazer. Esses documentos foram identificados. O que não pude perceber é se esses documentos foram aprovados na Câmara Municipal de Nova Lima e se estão vigentes.

No aspecto formal e estrutural, por meio desses documentos percebi como a gestão das políticas públicas de esporte e lazer é sistematizada, a partir das leis e premissas do município para essa área, lembrando que, segundo Requixa (1980) e Carvalho (s/d), é imprescindível que "as diretrizes gerais de uma política de lazer não [se restrinjam] apenas a uma política de atividades, mas [contemplem] também questões relativas à formação e reciclagem de quadros para atuação aos espaços e equipamentos e critérios de ordenação do tempo" (apud MARCELLINO, 1996b, p. 28-29).

Nessa fase da coleta de dados estou mais propensa a identificar a política de esporte e lazer da cidade como uma política de atividades que acontecem de acordo com as demandas.

\section{As Ações, Programas e Projetos da SEMEL}

As 65 caixas visitadas na coleta de dados me proporcionaram identificar algumas questões importantes sobre a política pública de esporte e lazer na cidade. Foram muitas horas de acesso e leitura dos documentos. $\mathrm{O}$ trabalho de investigação foi intenso devido ao número de caixas e a forma na qual os documentos estão organizados. Não há uma sequência nos documentos, tão pouco uma organização cronológica, o que torna o trabalho de investigação exaustivo. Encontrei decretos, comunicações internas, leis, relatórios, atas de reunião, solicitações de empenho e demandas de serviços, 
projetos e procedimentos de programas, organização de eventos, dentre outros que serão abordados aqui.

A partir dos documentos da Secretaria Municipal de Esporte e Lazer, posso inferir que algumas ações vão de encontro às diretrizes da Política de Esporte e Lazer da cidade contempladas no Plano Diretor, outras ainda não foram identificadas. Vou identificar esses arranjos à medida que explicitar a documentação a que tive acesso.

A primeira questão que gostaria de evidenciar sobre o que foi coletado se refere às atribuições e responsabilidades de forma geral da Secretaria estudada. Ela é responsável por gerir eventos na cidade de diferentes instâncias. Por exemplo, além dos eventos esportivos e campeonatos que já fazem parte do calendário da cidade como Jogos do interior de Minas Gerais (JIMI) e Jogos Escolares de Minas Gerais (JEMG), é responsável pela organização do Carnaval, do Desfile Cívico e comemorações do dia 7 de Setembro, pela manutenção e revitalização de campos e quadras da cidade, além de subsídios ao futebol amador, ao profissional da cidade e outros projetos e ações esporádicos.

Pude perceber um grande incentivo à prática do esporte na cidade, em especial ao futebol, por intermédio dos incentivos financeiros ao esporte rendimento da cidade que é o time do Vila Nova, com valores superiores a outras atividades. Isso foi observado no documento Lei 2303 de 26 de Dezembro de 2012 que estabelece incentivo financeiro às atividades esportivas no valor de $\mathrm{R} \$ 700.000,00$ e incentivo ao Vila Nova no valor de $\mathrm{R} \$ 800.000,00$ para o ano de 2013. Já para o ano de 2015, na Lei no. 2489 de 30 de janeiro de 2015, que Dispõe sobre concessão de auxílios, contribuições e ou subvenções sociais, o valor estimado para o Clube é de $\mathrm{R} \$ 2.000 .000,00$ sendo para as 
demais atividades esportivas, o montante de $\mathrm{R} \$ 3.000 .000,00$. Posso inferir desses dados que há um investimento grande na terceira instância do esporte, o de alto rendimento.

Salienta-se que, no período estudado, houve também um grande incentivo para o futebol amador, por intermédio da Liga de Desportos de Nova Lima que está diretamente relacionada à diretriz que prevê que a cidade deve "promover jogos e torneios que envolvam as associações comunitárias dos bairros, dos municípios vizinhos e de outros estados". A Secretaria promove esse tipo de evento, principalmente da modalidade Futsal. Há registros de campeonatos anuais de Futsal na cidade.

Todas as quadras e campos da cidade são revitalizados e mantidos por esta Secretaria, o que ocasiona uma demanda de serviço e de investimento alto nesse setor. Li alguns relatórios de vistoria de campos e quadras da cidade que totaliza 14 quadras e 15 campos de futebol, distribuídos nos bairros, além do Estádio Municipal Castor Cifuentes, e de 3 campos de iniciativa privada. Também foram identificados 40 times de futebol na cidade e uma Liga de desportos, além do time profissional, o Vila Nova Atlético Clube.

Dessa forma, observei que os itens "I. recuperação dos equipamentos de esporte, adequando-os à realização de eventos esportivos", o item III: "a ampliação e a otimização da capacidade dos equipamentos esportivos municipais" e o que compete o XVII. "assegurar o pleno funcionamento de todos os equipamentos, garantindo a manutenção de suas instalações" e ainda o item XX. "revitalizar e assegurar pleno funcionamento dos Poliesportivos Municipais" estão associados à manutenção de campos e quadras da cidade, que são realizadas de acordo com a demanda das comunidades e clubes esportivos para conserto, manutenção desses espaços públicos 
que se traduzem em consertar alambrados, pisos, gramados, vestiários, dentre outras necessidades.

De acordo com os documentos, esse processo de manutenção dos equipamentos era moroso, uma vez que demandava licitação. Sempre houve, dentro da Secretaria um setor responsável por estas questões, tendo em vista o volume dos equipamentos.

A gestão de 2013-2016 foi importante para o esporte e lazer, pelo volume de ações desenvolvidas. Uma das mais significativas foi a realização da I Conferência Municipal de Esporte e Lazer, no dia 19 de outubro de 2013, que contou com a participação da população. Antes da Conferência, propriamente dita, foram realizadas consultas à população, por intermédio de Pré-conferências promovidas nos bairros da cidade.

Tratou-se de um movimento importante, uma vez que um ciclo de conferências de esporte e lazer pode ser usado como excelente instrumento de diagnóstico, capaz de balizar as fases iniciais da elaboração de políticas públicas. Isso porque são capazes de favorecer a demonstração de interesses e desejos por meio de participação democrática.

As regras da Conferência foram definidas em regimento interno que estabeleceu participação de todos os cidadãos e cidadãs, desde que se inscrevessem para tal. A temática do encontro abrangeu: 1) proposta de regulamentação da Política Municipal de Esporte e Lazer (diretrizes) e o Sistema Municipal de Lazer, 2) Plano Municipal de Lazer, 3) Gestão colegiada dos equipamentos do esporte e lazer e universalização das práticas esportivas, 4) Eleição dos membros do Conselho Municipal do Esporte e Lazer. Esses temas foram inseridos no Art. $2^{\circ}$. do Decreto ${ }^{\circ}$ 5458, de 20 de setembro de 2013 - Convoca a $1^{\mathrm{a}}$. Conferência Municipal do Esporte e Lazer, além de dar outras providências. 
A Conferência foi organizada na forma de plenárias e grupos de trabalho. Foram divididos três grupos temáticos, sendo eles: a) Grupo I: diretrizes da Política Municipal de Esporte e Lazer e o Sistema Municipal de Esporte e Lazer; b) Grupo II: Plano Municipal de Esporte e Lazer e c) Grupo III: gestão colegiada dos equipamentos de Esporte e Lazer e universalização das práticas esportivas. Dessa forma, os temas foram discutidos nos grupos e, logo após, houve uma plenária para aprovação das resoluções. Segundo Araújo (2014), nesse espaço democrático de discussão do esporte e lazer do município, foram discutidas e aprovadas as diretrizes da Política Municipal do Esporte e do Lazer; o Sistema Municipal do Esporte e do Lazer; o Plano Municipal do Esporte e do Lazer; realizou-se a eleição dos conselheiros efetivos e suplentes, representantes da sociedade civil e houve indicação dos conselheiros efetivos e suplentes, representantes do Governo Municipal.

Alguns documentos explicitaram as diretrizes da Política Municipal de Esporte e de Lazer discutidas e aprovadas nesta Conferência, levando ao entendimento de que elas consideraram o esporte como um direito social, cabendo ao município estimular, possibilitar e assegurar o exercício da prática esportiva e de lazer aos seus habitantes.

Há avanços na descrição dessas diretrizes e uma aproximação ao que está preconizado nas diretrizes do Plano diretor da cidade. Ressalto, assim, que a Política Municipal de esporte e lazer discutida e definida na $1^{\mathrm{a}}$. Conferência de esporte e lazer de Nova Lima busca garantir a acessibilidade às práticas esportivas e de lazer, contempla as três formas de manifestação do esporte, sobretudo o esporte recreativo e de lazer. Destaca o apoio e o fomento a iniciativas populares para disseminação do esporte, assim como a participação da sociedade civil nas diferentes etapas da política pública; propõe uma avaliação da relação com o time profissional da cidade e as contrapartidas 
envolvidas nesse encontro. Mostra a contínua preocupação com a manutenção dos espaços para as vivências esportivas e de lazer, dentre outras questões. Vale ressaltar as iniciativas inovadoras de garantia do desenvolvimento da memória do esporte e do lazer para as futuras gerações e a manutenção dos bens naturais da cidade, além da proposição de atuação intersetorial. Isso nos mostra que as diretrizes da Política Municipal de esporte e lazer da cidade vão ao encontro ao Plano Diretor municipal.

É plausível inferir, também, que a Conferência se caracterizou como uma tentativa de atender a diretriz XI, que trata de "incentivar a prática de esportes na rede escolar municipal, através de programas integrados à disciplina Educação Física”. Tal afirmação justifica-se, pois foi possível verificar que a Conferência apresentou uma tentativa de implantar um sistema que fosse capaz de garantir um currículo básico para as aulas de educação física nas escolas, fomentando a realização de jogos escolares. $\mathrm{Na}$ programação do encontro foi dedicado tempo específico para discussão desta temática, a partir de grupos de trabalho.

Uma importante diretriz contemplada no Plano Diretor da cidade que se refere à Criação do Conselho Municipal de Esporte e Lazer e implantação do Fundo Municipal de Esporte e Lazer. Posso inferir que o Conselho Municipal de Esportes foi criado, por intermédio da Lei no. 1996 de 6 de Julho de 2007 que dispõe sobre a criação, composição e funcionamento do Conselho Municipal de Esporte e Lazer de Nova Lima. O documento mais atualizado sobre o Conselho diz respeito ao Decreto no. 5.621, de 29 de Janeiro de 2014 que "nomeia os membros do Conselho Municipal de Esporte e Lazer, o CMEL". De acordo com esse decreto, há representantes governamentais e representantes da sociedade civil e também define que a competência, mandato e todas 
as regras de funcionamento do Conselho foram definidos na Conferência Municipal de Esporte e Lazer.

As festas e eventos da cidade são organizados por esta Secretaria. Portanto, o Carnaval, a Festa do Peão Boiadeiro, Minimaratona de aniversário da cidade, Arraial Nova-limense, Festival de Pipas, "Gincana do Vovô e da vovó", "Programa na medida", as comemorações e desfile Cívico do dia 7 de Setembro estão na pauta de eventos promovidos e subvencionados com recursos públicos. Os documentos analisados, por exemplo, compuseram-se de várias prestações de contas de blocos carnavalescos e duas escolas de samba da cidade. Outros eventos de demais Secretarias ou Departamentos da Prefeitura contam com apoio da Semel na organização: parcerias com Coordenadoria de Idosos, da Juventude, Pessoa com deficiência, da diversidade (LGBT) e da igualdade racial e remetem ao objetivo de atender às diretrizes XII. "implementar e apoiar iniciativas de projetos específicos de esporte e lazer para todas as faixas etárias", XVI. "ampliar os programas de eventos poliesportivos e de lazer e entretenimento", $\mathrm{X}$. "garantir a toda população, condições de acesso e de uso dos recursos, serviços e infraestrutura para a prática de esportes e lazer".

O programa "Comunidade Ativa" chamou a atenção e relaciona-se às diretrizes V. “incentivar a prática esportiva e recreativa, propiciando condições de desenvolvimento pessoal e social”, VI. “orientar a população para a prática de atividades em áreas verdes, parques, praças e áreas livres" e ainda à VII. "estimular a prática de jogos tradicionais populares" na medida em que se caracteriza como um programa de iniciação esportiva que promove aulas de diferentes modalidades esportivas em núcleos na cidade. Pelo que pude perceber nos documentos, o programa 
contemplava aulas de futsal, basquete, handebol e voleibol, com horários específicos nos quais os profissionais de educação física atuavam dando aulas nos núcleos.

Envolvia ainda atividades de Colônia de Férias e acompanhamento dos profissionais nas Academias a Céu Aberto na cidade em horários de "pico". Não é um programa original da gestão analisada, há documentos que me mostraram que este programa já existia no ano de 2002.

Encontrei registro de fichas de inscrição e documentação de crianças (inclusive com autorização dos responsáveis) para participação nas colônias de férias e escolinhas esportivas, respectivamente. Documentos do horário das aulas e uma folha de assinaturas que marcava presença dos profissionais contratados, que eram acompanhados pelo pessoal da Secretaria. Não consegui evidência de reunião desses professores, nem tampouco de formação profissional, uma temática importante dentro do campo do lazer pois profissionais qualificados auxiliam no entendimento e vivência do lazer enquanto direito social. Para Isayama et.al (2011) o processo de formação profissional no lazer vem ganhando espaço tanto no meio acadêmico quanto nas políticas públicas vigente e pode "contribuir como eixo privilegiado de intervenção com vistas a contribuir nos processos sociais, políticos, históricos e culturais que integram as práticas de lazer" (ISAYAMA et.al, 2011, p. 211). Assim, ao invés de meros reprodutores de práticas, esses profissionais são fundamentais para o entendimento e a disseminação do lazer como direito.

É possível afirmar que algumas atividades de lazer acontecem de acordo com a demanda. É o caso das ruas de lazer que são solicitadas por diferentes segmentos e organizações: vereadores, associações de bairro, comunidade religiosa, igrejas, organização não governamental, times de futebol, dentre outros. Elas são uma grande 
demanda em especial no mês de Outubro, em função do dia das crianças. Percebo uma tentativa em atender a essa demanda nos documentos, mas acredito que há uma fragilidade no que tange à diretriz XXII. "manter e ampliar o programa de ruas de lazer, promovendo atividades de esportes, lazer e recreação".

Já em consideração ao item II. referente às pessoas com necessidades especiais, vi um planejamento administrativo do Programa Superar, que é uma política pública para pessoas com deficiência da cidade de Belo Horizonte e uma solicitação de implantação do "Comunidade Paralímpica" que não apresentou mais documentação relacionada, me levando a concluir que foram realizadas ações pontuais para atender a esse público, pois foram poucas as referências/documentos encontrados.

Não foi possível, até o momento, detectar algumas premissas citadas no Plano Diretor, como por exemplo, a de construção do Centro Olímpico Municipal, da parceria de escolinhas de futebol e ainda de construção de ciclovias, rampas de skate e piscinas olímpicas nos poliesportivos municipais.

\section{Considerações Finais}

O objetivo desse estudo é compreender as políticas públicas de esporte e lazer na cidade de Nova Lima na gestão municipal que envolve o período de 2013 a 2016. Para isso recorri à análise documental e pesquisa de campo. Essas considerações se constituem como primeiras análises dos documentos encontrados na coleta de dados.

Em primeiro lugar, é importante destacar que a cidade tem um órgão responsável pelo desenvolvimento do lazer e do esporte desde 1997, o que é relevante, pois demonstra uma preocupação em atender as demandas da população nesse sentido. 
Como considerações resultantes da coleta de dados, posso inferir que foi possível detectar um volume de ações, projetos e eventos que tentam oportunizar o acesso ao bem cultural que é o lazer. Entretanto, as ações são de caráter eventual e não de caráter contínuo. Os programas não são institucionalizados. Muitos se apresentam como ações isoladas, não se organizam em uma política de lazer concisa, articulada e bem delimitada. Isayama e Peres (2014) ponderam que essa problemática da descontinuidade das políticas públicas não é particular das políticas esportivas. "Historicamente, as políticas sociais brasileiras têm se pautado pela fragmentação e ou descontinuidade, ficando a cargo das mudanças de governo" (ISAYAMA; PERES, 2014, p. 229).

O programa Comunidade Ativa, parece ser uma tentativa nesse sentido, pois além de escolinha de esportes, inclui ações na perspectiva de atender as demandas da comunidade através de quatorze núcleos situados nos bairros da cidade.

Outro aspecto relevante como tentativa de se estabelecer a política de lazer da cidade se refere à Conferência Municipal de Esporte e Lazer da cidade realizada em 2013. Foi uma tentativa de assegurar a participação popular na formulação da política, no desenvolvimento dos programas e projetos. Nesse evento foram discutidos o Sistema Municipal de Esporte e as diretrizes da política municipal de esporte e lazer, a gestão colegiada dos equipamentos do esporte e a universalização das práticas esportivas. Portanto, existe um Sistema municipal do esporte e lazer da cidade de Nova Lima.

O esporte na cidade é tratado a partir das suas três perspectivas: rendimento, educacional e esporte recreativo. Observei que, em termos de recursos destinados a cada um deles, o esporte rendimento tem destaque em detrimento dos demais, mas apenas em uma modalidade esportiva: o futebol de campo, pois há um financiamento expressivo 
para essa área. Merece a atenção a maior importância que é dada ao futebol em comparação aos demais esportes que podem ser vivenciados como manifestação cultural do lazer. Há uma cultura muito grande de futebol /futsal na cidade, mantendo outras modalidades de esporte à margem das ações. Isso pode ser comprovado pela importância e amplitude do Campeonato de Futsal nova-limense.

Quanto à formação dos profissionais do lazer não há indícios de que elas aconteciam, nem com a presença de aproximadamente 70 professores envolvidos nas ações e aulas do Programa Comunidade Ativa. Em relação aos equipamentos de lazer da cidade, há um setor específico para manutenção de campos e quadras. Não identifiquei ações que contemplassem outros espaços específicos para a vivência do lazer como parques e praças públicas.

Essas considerações são análises da trajetória da administração pública de lazer na cidade, que é gerida de acordo com interesses políticos que denotam falta de continuidade, pois a política pública tem associação direta com a política de governo. Portanto, as políticas são, sobretudo, de governo, e não políticas de Estado. Historicamente, as políticas sociais brasileiras têm se pautado pela fragmentação e ou descontinuidade, ficando à mercê das mudanças de governo. Isso ficou perceptível no município estudado, em que as políticas se modificam a cada mudança de gestão, com descontinuidades que prejudica as ações. Ao estudar o caso de Nova Lima, tenho a impressão de falar de várias políticas de lazer e não apenas uma, com diretrizes e ações consolidadas. 


\section{REFERÊNCIAS}

AMÁBIle, A. E. N. et al. (Org.). Dicionário de Políticas Públicas. Barbacena, EdUEMG 2012.

ALVES-MAZZOTTI, Alda Judith; GEWANDSZNAJDER, Fernando. O método nas ciências naturais e sociais: pesquisa quantitativa e qualitativa. São Paulo: Pioneira, 1998.

ANGLOGOLD ASHANTI. História. Disponível em: https://www.anglogoldashanti.com.br/. Acessado em 19/04/2015

ARAÚJO, Letícia Cristina Silva. A Secretaria Municipal de Esporte e Lazer em foco: ano um de gestão na área do esporte. Nova Lima: Prefeitura Municipal de Nova Lima, 2014.

BONALUME, Cláudia Regina; ECHER, Silvana Regina. IV Seminário Nacional de Políticas Públicas em Esporte e Lazer - Participação Popular: Governo e População Partilhando o Poder da Decisão. In: LIBERATO, Almir; SOARES, Artemis. (Orgs.). Seminário Nacional de Políticas Públicas de Esporte e Lazer - retrospectiva histórica. Manaus: EDUA, 2009. p. 53-74.

FILHO, Lino Castellani. Gestão municipal e política de lazer. In: ISAYAMA, Hélder, LINHALES, Meily Assbú (Orgs.). Sobre lazer e política. Maneiras de ver maneiras de fazer. Belo Horizonte: Editora UFMG, 2006. p. 119-135.

FREY, Klaus. Políticas públicas: um debate conceitual e reflexões referentes à prática da análise de políticas públicas no Brasil. In: Planejamento e políticas públicas n. 21 Jun-2000.

GOMES, Christianne Luce (Org.). Dicionário crítico do lazer. Belo Horizonte: Autêntica Editora, 2004.

GOMES, Christianne Luce. Lazer: necessidade humana e dimensão da cultura. In: Revista Brasileira de Estudos do Lazer, Belo Horizonte, v.1, n.1, p. 3-20, jan;abr 2014.

GOMES, Elmo. A história de Nova Lima. Disponível em: https://historianovalima.no.comunidades.net/ Acesso em: 20 abr. 2015.

ISAYAMA, Hélder Ferreira; PERES, Fabiano Antônio Sena. História e políticas públicas de esporte e lazer em Minas Gerias: o caso da Secretaria de Desenvolvimento Social e Esportes (2003-2006). In: RODRIGUES, Marilita Aparecida Arantes, ISAYAMA, Hélder Ferreira (Org.). Um olhar sobre a trajetória das políticas públicas de esporte em Minas Gerais: 1927 a 2006, 2014.

ISAYAMA et al. Lazer, políticas públicas e formação profissional: análise da política de formação profissional de secretarias de Esportes em municípios da região 
metropolitana de Belo Horizonte. IN: ISAYAMA et al. (Orgs). Gestão de políticas de esporte e lazer. Belo Horizonte: Editora UFMG, 2011.

LINHALES, Meily Assbú et al. Esporte e lazer na Grande-BH. Por onde caminham as gestões públicas? In: ISAYAMA, Hélder, LINHALES, Meily Assbú (Orgs.). Avaliação de políticas e políticas de avaliação: Questões para o esporte e o lazer. Belo Horizonte, Editora UFMG, 2008. 209 p.

MARCEllinO, Nelson Carvalho (Org.). Políticas Públicas setoriais de lazer. O papel das prefeituras. Campinas, São Paulo: Autores Associados, 1996. (Coleção Educação Física e Esportes), 133 p.

O entendimento do lazer. In: MARCELLINO, Nelson Carvalho (Org.). Políticas Públicas setoriais de lazer: $\mathrm{O}$ papel das prefeituras. Campinas, São Paulo: Autores Associados, 1996. (Coleção Educação Física e Esportes). P. 1-5.

MARCELLINO, Nelson Carvalho . O lazer e os espaços na cidade. In: ISAYAMA, Hélder, LINHALES, Meily Assbú (Orgs.). Sobre lazer e política: Maneiras de ver, maneiras de fazer. Belo Horizonte: Editora UFMG, 2006. P. 65-92.

MARQUES, Eduardo; FARIA, Carlos Aurélio Pimenta de (Orgs.) A política pública como campo multidisciplinar. Rio de Janeiro: Editora Fiocruz, 2013.

MARSHAL, T. H. Cidadania, classe social e status. Rio de Janeiro: Zahar Editores, 1967.

MENICUCCI, Telma. Políticas Públicas de Lazer. Questões analíticas e desafios políticos. In: ISAYAMA, Hélder, LINHALES, Meily Assbú (Orgs.). Sobre lazer e política: Maneiras de ver, maneiras de fazer. Belo Horizonte: Editora UFMG, 2006. P. 136-164.

NOVA LIMA - Minas Gerais - MG - Histórico. In: https://biblioteca.ibge.gov.br/visualizacao/dtbs/minasgerais/novalima.pdf . Acesso em: 23 mar. 2015.

NOVA LIMA. Plano Diretor, Lei no 2007, de 28 de agosto de 2007.

PINTO, Leila Mirtes Santos de Magalhães. Apresentação. In.: RODRIGUES, Marilita Aparecida Arantes; ISAYAMA, Helder Ferreira (Orgs.). Um olhar sobre a trajetória das políticas públicas de esporte em Minas Gerais: 1927 a 2006. Contagem: MJR Editora Gráfica, 2014.

RAMALHO JR, Álvaro. Coeficiente de Gini. In.: CASTRO, Carmem Lúcia Freitas de; GONTIJO, Cynthia Rubia Braga; AMABILE, Antônio Eduardo de Noronha (Orgs). Dicionário de políticas públicas. Barbacena: EdUEMG, 2012. P. 74-77

RODRIGUES, Marilita Aparecida Arantes; ISAYAMA, Helder Ferreira (Orgs.). Um olhar sobre a trajetória das políticas públicas de esporte em Minas Gerais: 1927 a 2006. Contagem: MJR Editora Gráfica, 2014. 
RODRIGUES, Marilita Aparecida Arantes, COSTA, Luciana Cirino Lages Rodrigues. Diretoria de Esportes de Minas Gerais: suas políticas, sua história (1946-1987). In: Um olhar sobre a trajetória das políticas públicas de esporte em Minas Gerais: 1927 a 2006. RODRIGUES, ISAYAMA (Orgs.). Contagem: MJR Editora Gráfica, 2014, p.47118.

SANTOS, Flávia da Cruz. Procurando o lazer na constituinte: sua inclusão como direito social na constituição de 1988. Dissertação. Faculdade de Educação Física da Universidade Estadual de Campinas, Campinas, 2011.

SANTOS, Flávia da Cruz. O lazer como direito social: sua inclusão na Constituição de 1988 In: Enarel - ENCONTRO NACIONAL DE RECREAÇÃO E LAZER, 25, 2013. Anais ... Ouro Preto, Minas Gerais.

SILVA, Débora Alice Machado da, et al. Gestão de políticas públicas de esporte e lazer: princípios e pressupostos teóricos. Brasília: Gráfica e Editora Ideal, 2011a. 62 p. (Cadernos interativos - elementos para desenvolvimento de políticas, programas e projetos intersetoriais, enfatizando a relação lazer, escola e processo educativo, 2.)

SILVA, Débora Alice Machado da, et al. Sistema Nacional de Esporte e Lazer. Brasília: Gráfica e Editora Ideal, 2011b. 40 p. (Cadernos interativos - elementos para desenvolvimento de políticas, programas e projetos intersetoriais, enfatizando a relação lazer, escola e processo educativo, 3 ).

SILVA, Dirceus Santos; BORGES, Carlos Nazareno Ferreira; AMARAL, Silvia Cristina Franco. Gestão de polícias públicas do Ministério do Esporte do Brasil. In: Revista Brasileira de Educação Física e Esporte v. 29, n. 1, São Paulo, Jan/Mar 2015.

SOUZA, Celina. Políticas públicas: uma revisão da literatura. In: Sociologias, Porto Alegre, ano 8, n.16, jul./dez 2006, p.20-45.

SOUZA, Renata Couto de. Um modelo de implantação de políticas públicas de turismo: O Caso de Nova Lima - MG. Rio de Janeiro: Livre Expressão, 2013, 300p.

STAREPRAVO, Fernando Augusto; SOUZA, Juliano de; MARCHI JUNIOR, Wanderley. Políticas públicas de esporte e lazer no Brasil: uma proposta teóricometodológica de análise. In: Revista Movimento, Porto Alegre, v. 17, n. 03, p. 233 251, jul./set de 2011 .

SUASSUNA, Dulce Maria F. de A et al. O Ministério do Esporte e a definição de políticas para o esporte e lazer. In: SUASSUNA, Dulce Maria F. de A.; AZEVEDO, Aldo Antônio de (Orgs.). Política e lazer: interfaces e perspectivas. Rede Cedes. Brasília: Thesaurus, 2007. p. 13-42.

VIANA, Juliana de Alencar; OLIVEIRA, Rita Márcia de. Secretaria de Esportes, Lazer e Turismo - Minas Gerais (1983-1996): vestígios de uma história. In.: RODRIGUES, Marilita Aparecida Arantes; ISAYAMA, Helder Ferreira (Orgs.). Um olhar sobre a trajetória das políticas públicas de esporte em Minas Gerais: 1927 a 2006. Contagem: MJR Editora Gráfica, 2014. 


\section{Endereço da Autora:}

Aládia Cristina Rodrigues Medina

Alameda Carlos Drumond de Andrade, 309 Bairro Quintas II

Nova Lima - MG - 34.003-318

Endereço Eletrônico: aladiamedina34@gmail.com 